\title{
Do ICU Diaries Build an Accurate Narrative of the Patients Journey? Year 2015- 2016
}

\author{
Ms. Rebekah Thomson, Dr. Nawaf Al Subaie \\ Cardiothoracic Intensive Care \\ Atkinson Morley Wing \\ St Georges NHS Foundation Trust \\ Blackshaw Road, London
}

\begin{abstract}
:
Implementation of patient diaries in critically ill patients is now widely adopted within the United Kingdom. The benefits include a reduction in post-traumatic stress disorder and can be useful in patients rehabilitation, however the information included in the diaries influences the value. An audit was completed of the entries to establish the 'quality' of the diaries, 18 months after implementation.
\end{abstract}

Methods: The number of patient admissions to the 18 bed, intensive care unit whose stay exceeded $>72$ hours, were recorded over a 12 months period. Patients were screened for diary implementation. Those diaries were further screened for number of entries and the profession of entrants.

Results: $33.8 \%$ of patients with a length of stay $>72$ hours were commenced on the patient diary scheme. Increased length of stay (LOS) and Intensive Care National Audit and Research (ICNARC) generated score were associated with diary use. Total number of entries correlated with LOS $(p=0.05)$. Age did not influence instigation.

Conclusion: The diaries analysed did not always reflect the patient's duration of stay and did not include a multidisciplinary approach. The quality of patient diaries needs to improve if they are to be of benefit in rehabilitation.

Keywords: Intensive Care, Patient Diary, Post-traumatic stress disorder, rehabilitation

\section{INTRODUCTION}

Many patients who have experienced critical illness have no or limited recollection of their time in ICU. Memories of the ICU are often vivid, realistic and frightening [1], although they are often disjointed and frequently delusional. Further nightmares and hallucinations make it difficult for patients to make sense of their experience.

There are often gaps in patient's recollection with the lack of appreciation to the severity of their illness, which leads to unrealistic expectations regarding the speed and extent of their recovery [2]. Anxiety and depression, contributed to by cognitive impairment and memory disturbances, are often described post ICU survival and can impair recovery $[3,4]$. These experiences can lead to neurophysiological consequences, which can influence health related quality of life and trigger posttraumatic stress disorder [5].

This is psychiatric disorder triggered by a traumatic experience [6] that can cause flashbacks of events and future avoidance of situations. Post-traumatic stress disorder (PTSD) causes the sufferer to reexperience distressing situations or events leading to symptoms of increased arousal [7]. It is suggested that 1 in 10 patients with an ICU stay greater than 48 hours suffers from PTSD [1].

The National Institute of Clinical Excellence (NICE) [8] recommends that rehabilitation plans be implemented as soon as possible once a patient is admitted to critical care. These plans should address 
the physical and psychological symptoms that occur as a result of an episode in ICU, to equip patients with a greater understanding of what has happened during their stay. Compiling a narrative of the events in ICU can assist this process and reduce PTSD, and this forms the foundation and wide adoption of a patient diary.

The use of patient diaries were first introduced in the 1980's in Denmark and was later adopted in the UK in the 1990's [9]. It is a cost effective tool that allows patients to make sense of their experiences and distinguish between reality and imagination by connecting memories to recorded events [10]. It can also improve communication between relatives and health care professionals, as some centers encourage relatives and loved ones to add entries to the diary [3].

Much of the research on the use of a patient diary concentrates on the association with diary implementation and patient outcomes. These diaries can reduce the incidence and assist in treating PTSD. A recent randomized controlled trial demonstrated a significant reduction in the incidence of PTSD when patient diaries are used $(5 \%$ vs. $13 \%, p=0.02)$ [2]. Patient diaries are currently used in many UK ICUs and other European countries to reduce PTSD and improve patient rehabilitation [11, 12].

To ensure diaries have a positive impact on outcome or for diaries to be of use to patients, the diary must be complete. The aim of this study is to assess the number of entries in each diary to evaluate the quality of the narrative, including the professional completing the entries. A future aim is to investigate any possible patient related factors that are associated with adherence to diary implementation in a post analysis survey at a later date.

\section{MethodS}

The data presented in this manuscript is from our unit, which has 18- beds, and consists of level 2 and level 3care, which differentiates between high dependency patients and intensive care patients. It has a nursing ratio of $1: 1$, which is provided in the majority of time, dependent on levels of acuity. The clinical team currently comprises of 114 nurses, 10 consultants, 2 of which are on duty daily, 14 junior doctors who spend a minimum of 3 to 6 months in ICU and many allied health care professionals, such as physiotherapists, speech and language therapists and occupational therapists cover ICU as well as other units. All healthcare professionals are encouraged to complete patient diaries to ensure that the narrative of events is multidisciplinary and reflects the team influence on patient recovery.

The analysis of this data was intended to appraise the patient diary service and therefore local approval from the hospital trust was sought for this evaluation, all diaries analyzed were anonymous and were hospital property prior to distribution to patients.

Patient diaries, in conjunction with patient follow up clinics, were introduced 18 months before the study. A diary is started if the patient's stay is, or perceived to be $>72$ hours. A working group of designated nurses introduced and championed the implementation of diaries as part of a team project. The roll out of the project included emails, information sharing during nurse handover, expert user sessions and a poster campaign.

The number of ICU admissions was recorded over a 12 months period. June 2015-June 2016 was selected to allow a 6 month post implementation process settle down. Those that had a duration of stay $>4$ days were screened for diary implementation. $>4$ days was chosen to exclude patients discharged between day 3 and day 4. Demographic data and patients characteristics were collected from an electronic database. . The levels and patterns of contributions to the patient diary were examined as the initial aim; the compliance with diary instigation, nurse's adherence to daily entries, the number of medical team entries, allied healthcare entries and relative's entries were collated as the $2^{\text {nd }}$ aim. We also retrospectively looked at how many patient diaries were returned to patients during rehabilitation as the $3 \mathrm{rd}$ aim.

The diaries were analyzed for number and source of entries.

Diaries that were available for review or originals scanned were included in the final data. 


\section{ReSUlts}

There were 1607 admissions in the first 12 months from diary initiation. Of those, 318 admissions lasted > 4 days, which should demonstrate diary initiation. There were 11 patients who were readmitted, resulting in 306 patients for analysis. A diary was commenced in 104 patients (33.8\%). A total of 74 diaries were available for analysis $(71 \%)$. Other diaries were misplaced or destroyed due to lack of entries.

There was no difference in age between patients who had diaries and those who did not $(64.5 \pm 14.3$, $67.4 \pm 13.7), p=0.12)$. Gender did not influence diary instigation. There was a difference in the length of stay ( 6 vs. $12, \mathrm{p}=<0.05$ ). There was no difference in diary implementation between planned and non-planned ICU admissions (168 (74.1\%) vs. $57(74 \%), \mathrm{p}=0.48)$.

Of the diaries that were completed a total 1173 entries were made, $988(84.22 \%)$ entries were made by nursing staff compared to8 $(0.68 \%)$ by allied health care professionals, $22(1.87 \%)$ by medical staff and $128(10.91 \%)$ by loved ones. The median number of entries by nursing staff was 10 (IQR 12) (table 2), despite the median length of stay being 12 (IQR 11) days. The duration of stay did not reflect daily entries by nursing staff (graph1).

10 diaries have been returned to patients, 22 patients died in hospital prior to discharge and diaries were unable to be returned. The other diaries remain in the ICU awaiting return to their respective patients.

Table 1. Demographics of patient diary implementation on CTICU.

\begin{tabular}{|c|c|c|c|}
\hline \multirow{3}{*}{ Gender } & & No diary $(n=232)$ & Diary $(\mathrm{n}=74)$ \\
\hline & Female & $57(24.6 \%)$ & $22(29.7 \%)$ \\
\hline & Male & $175(75.4 \%)$ & $52(70.3 \%)$ \\
\hline \multicolumn{2}{|l|}{ Age (mean) } & 67.4 (s.d. 13.7) & 64.5 (s.d.14.3) ( $\mathrm{p}=0.12)$ \\
\hline \multirow[t]{6}{*}{ Speciality } & Cardiothoracic & $76(32.8 \%)$ & $17(23 \%)$ \\
\hline & Cardiology & $51(22 \%)$ & $32(43.2 \%)$ \\
\hline & Medical & $35(15.1 \%)$ & $12(16.2 \%)$ \\
\hline & Trauma & $8(3.4 \%)$ & $2(2.7 \%)$ \\
\hline & Vascular & $49(21.1 \%)$ & $5(6.8 \%)$ \\
\hline & Other & $13(5.6 \%)$ & $6(8.1 \%)$ \\
\hline $\begin{array}{l}\text { Severity scores } \\
\text { (median) }\end{array}$ & ICNARC & 21 & $24(\mathrm{p}=<0.05)$ \\
\hline \multirow{3}{*}{$\begin{array}{l}\text { Planned ICU } \\
\text { admission }\end{array}$} & Planned & $60(25.9 \%)$ & $16(21.6 \%)$ \\
\hline & No plan & $168(74.1 \%)$ & $57(74 \%)(\mathrm{p}=0.49)$ \\
\hline & Unknown & & $1(1.35 \%)$ \\
\hline \multicolumn{2}{|l|}{$\begin{array}{l}\text { LOS days } \\
\text { (median) }\end{array}$} & 6 & $12(\mathrm{p}=<0.05)$ \\
\hline \multirow{3}{*}{$\begin{array}{l}\text { Hospital } \\
\text { Outcome }\end{array}$} & Survived & $168(72.4 \%)$ & $49(66.2 \%)$ \\
\hline & Died & $64(27.6 \%)$ & $22(29.0 \%)$ \\
\hline & Unknown & 0 & $3(4.1 \%)$ \\
\hline
\end{tabular}

Table 2. Median record and percentages of entries by relationship

\begin{tabular}{|l|c|c|}
\hline & Median [IQR] & Number of entries \\
\hline Total entries & $10[12]$ & $1173(100 \%)$ \\
\hline Nurse & $8[12]$ & $988(84.22 \%)$ \\
\hline Allied health professionals & $0[0]$ & $8(0.68 \%)$ \\
\hline Doctor & $0[0]$ & $22(1.87 \%)$ \\
\hline Relatives & $0[2]$ & $128(10.91 \%)$ \\
\hline
\end{tabular}


Graph 1. Correlation between LOS and number of entries

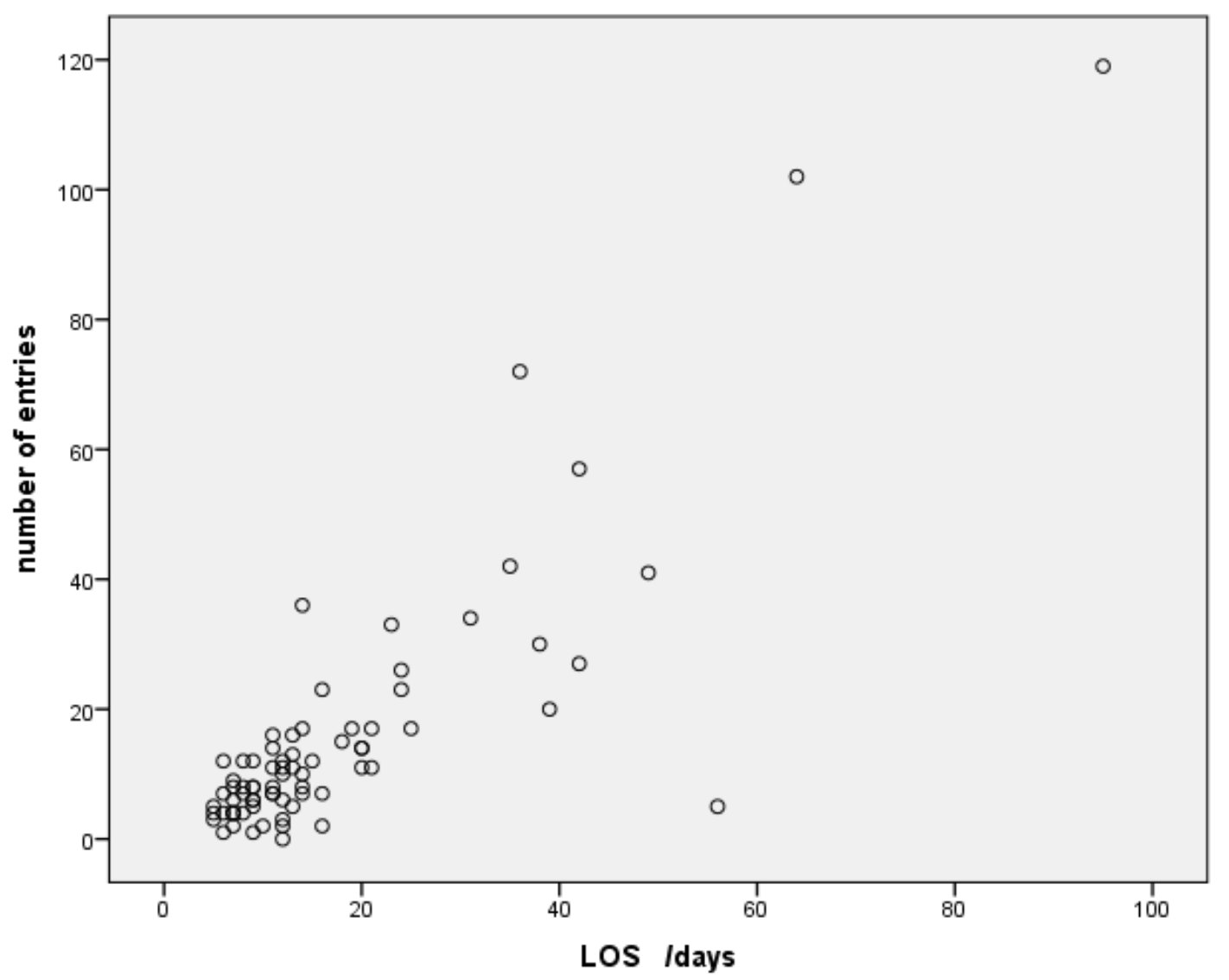

\section{DisCUSSION}

Patient diaries were implemented in $33.8 \%$ of ICU admissions with a length of stay $>4$ days. There was no discrimination based on age or gender. Diaries were implemented in patients with a higher severity score and those with an increased length of stay, though most diaries were not completed on a daily basis. The multidisciplinary team is not currently making regular entries in the diaries to describe pinnacle moments in their rehabilitation and recovery.

The rate of diary initiation is likely to be attributed to the nursing staff ability to instigate diaries in patients with higher severity scores and increased length of stay, excluding patients that are likely to be discharged in the next couple of days (12 days vs. 6).

Though severity of illness scores are not always accurate in predicting length of stay [13], patients that survive $>72$ hours with a higher severity of illness, using the ICNARC score, had a longer ICU stay within this unit. Patients with a greater severity of illness are likely to experience extended periods of time lost to unconsciousness and decreased awareness due to prolonged sedation, which can lead to increased episodes of delirium [14], this necessitates a need to describe ICU events to aid recovery.

There is some evidence suggesting duration of delirium and APACHE II, a severity scoring system, are not associated directly with PTSD [15], however building a narrative of events in patients without PTSD is also of benefit to aid rehabilitation.

Though patient diaries have been initiated effectively in appropriate patient groups, the number of entries is severely lacking in order to build a daily account of the patients stay. This could be related to multiple barriers, including awareness of diaries for visiting teams and/or rotating junior doctors, availability of time to complete an entry and the additional workload. Or the professional's difficulty in knowing what to write including legalities involved in patient documentation. We are currently undertaking a questionnaire for all multidisciplinary team members to gain a greater understanding into why diaries are not being regularly completed. 
This is of great importance as some diaries could not be returned to patients as they had such little entries, $<3$, and the team felt these did not reflect the patients stay accurately or showed the level of care the patient received, thus not contributing to a greater understanding of their severity of illness or ICU journey. Further work is needed to gain participation from our MDT into improving the patient diary service.

Many diaries were not returned as the patient was un-contactable and/or they have not returned to the follow up clinic. 2 diaries have subsequently been returned to the family of deceased patients at their request. We will be working towards distributing diaries whilst patients remain in hospital post ICU, this is to be led by the ICU follow up liaison team.

Patient diaries are necessary to 'fill in the gaps' of a patient's journey throughout critical illness, especially those who are at an increased risk of prolonged or increased level of sedation, and/or who develop delirium.

The introduction of patient diaries has been challenging. Patient diaries increase workload and can be difficult for staff to know what to write. Diary completion consisted of sporadic entries and did not always build an accurate narrative of the patient's ICU stay.

\section{REFERENCES}

[1] JONES C. GRIFFITHS RD. HUMPHRIS G (2000). Disturbed memory and amnesia related to Intensive Care. Memory; 8: 79-94

[2] JONES C. GRIFFITHS RD. HUMPHRIS G. SKIRROW PM (2001). Memory, delusions, and the development of acute posttraumatic stress disorder-related symptoms after intensive care. Crit Care Med; 29: 573-580

[3] ROULIN MJ. HURST S. SPIRIG R (2007). Diaries written for ICU patients. Qual Health Res; 17(7):893-901

[4] EDDLESTON JM. WHITE P. GUTHRIE E (2000). Survival, morbidity and quality of life after discharge from intensive care. Crit Care Med; 28: 2293-2299

[5] GRANJA C. LOPES A. MOREIRA S. DIAS C. COSTA-PEREIRA A. CARNEIRO A. JMIP Study Group (2005). Patients' recollections of experiences in the intensive care unit may affect their quality of life. Crit Care; 9(2): R96-R109

[6] American Psychiatric Association (AMA) (2000). Diagnostic and statistical manual of mental disorders- revised. 4. Washington, DC: American Psychiatric Association.

[7] JONES C. BACKMAN C. CAPUZZO M. et al.(2010). The RACHEL group. Intensive care diaries reduce new onset post traumatic stress disorder following critical illness: a randomised, controlled trial. Crit Care; 14(5): R168

[8] National Institute for Health and Care Excellence (NICE) (2009). Rehabilitation after critical illness in adults. Clinical Guideline [CG83]. London

[9] NYDAHL P, KNUCK D, EGEROD I (2011). The extent and application of patient diaries in German Intensive Care Units. Connect - The World of Critical Care Nursing. 7 (2): 122-126

[10] BACKMAN CG. WALTHER SM (2001) Use of a personal diary written on the ICU during critical illness. Intensive Care Med; 27(2):426-9

[11] EGEROD I. SCHWARTZ-NIELSON KH. HANSEN GM. LAERKNER E (2007). The extent and application of patient diaries in Danish ICUs in 2006. Nurs Crit Care. 12(3):159-67

[12] COMBE D (2005). The use of patient diaries in an intensive care unit. Nurs Crit Care;10(1):31-4

[13] MARIK PE. HEDMAN L (2000). Whats in a day? Determining intensive care unit length of stay. Crit Care Med; 28(6):2090-3

[14] American Psychiatric Association. Practice guidelines for the treatment of patients with delirium. Am J Psychiatry 1999; 156(5 suppl):1-20

[15] GIRARD TD, SHINTANI AK, JACKSON JC, et al (2007). Risk factors for posttraumatic stress disorder symptoms following critical illness requiring mechanical ventilation: a prospective cohort study. Crit Care, 11:R2 